\title{
Doped Heterojunction Used in Quantum Dot Sensitized Solar Cell
}

\author{
Yanyan Gao, Xiaoping Zou, and Zongbo Huang \\ Beijing Key Laboratory for Sensor, School of Applied Sciences, Beijing Information Science and Technology University, \\ Jianxiangqiao Campus, Beijing 100101, China \\ Correspondence should be addressed to Xiaoping Zou; xpzou2005@gmail.com
}

Received 19 February 2014; Revised 13 May 2014; Accepted 26 May 2014; Published 9 June 2014

Academic Editor: Dewei Zhao

Copyright (C) 2014 Yanyan Gao et al. This is an open access article distributed under the Creative Commons Attribution License, which permits unrestricted use, distribution, and reproduction in any medium, provided the original work is properly cited.

\begin{abstract}
Incorporated foreign atoms into the quantum dots (QDs) used in heterojunction have always been a challenge for solar energy conversion. A foreign atom indium atom was incorporated into PbS/CdS QDs to prepare In- $\mathrm{PbS} / \mathrm{In}$-CdS heterojunction by successive ionic layer adsorption and reaction method which is a chemical method. Experimental results indicate that $\mathrm{PbS}$ or $\mathrm{CdS}$ has been doped with In by SILAR method; the concentration of PbS and CdS which was doped In atoms has no significantly increase or decrease. In addition, incorporating of Indium atoms has resulted in the lattice distortions or changes of $\mathrm{PbS}$ or $\mathrm{CdS}$ and improved the light harvest of heterojunction. Using this heterojunction, Pt counter electrode and polysulfide electrolyte, to fabricate quantum dot sensitized solar cells, the short circuit current density ballooned to $27.01 \mathrm{~mA} / \mathrm{cm}^{2}$ from $13.61 \mathrm{~mA} / \mathrm{cm}^{2}$ and the open circuit voltage was improved to $0.43 \mathrm{~V}$ from $0.37 \mathrm{~V}$ at the same time.
\end{abstract}

\section{Introduction}

Doped quantum dot (QDs, semiconductor nanocrystal) which was fabricated by chemical method has been recently drawing great attention as a material for solar energy conversion. Incorporating foreign atoms can affect intrinsic property of semiconductor nanocrystals $[1,2]$. By doping foreign atom, it is possible to modify the electronic and photophysical properties of QDs [3]. In addition, it is also possible to tune the optical and electronic properties of semiconductor nanocrystals by controlling the type and concentration of dopants [4]. The versatile properties of doped QDs such as red-shift of light harvest [5], create of electronic states in the mid-gap region of the QD [6], and long time of an electron [7] make them attractive candidates for quantum dot sensitized solar cell (QDSC).

The doped single QDs have been researched. But incorporating foreign atoms into the quantum dot used in heterojunction has always been a challenge for solar energy conversion. In addition, one of the current challenges for high performance QDSC is the limited light absorption range from the visible to the near-infrared (NIR) region for the solar spectrum, so wider light absorption range has ability to generate extremely high $J_{\mathrm{sc}}[8]$. Recently, the light absorption range red shifts to $1100 \mathrm{~nm}$ from $900 \mathrm{~nm}$ when $\mathrm{PbS}$ quantum dot was doped as $\mathrm{Hg}-\mathrm{PbS}$ quantum dot, resulting in the short circuit current density $\left(J_{\mathrm{sc}}\right)$ remarkable increase. Although the $J_{\mathrm{sc}}$ have a remarkable increase, the open circuit voltage $\left(V_{\mathrm{oc}}\right)$ has no significant change [9]. While the $V_{\text {oc }}$ was increased when CdS/CdSe were doped as Mn-CdS/CdSe, the $J_{\mathrm{sc}}$ has no significant change [10]. How to improve the $J_{\mathrm{sc}}$ and the $V_{\mathrm{oc}}$ of QDSC is always a goal that many investigators pursue.

We introduced foreign atoms-indium atoms into $\mathrm{PbS} /$ CdS heterojunction [11-13] on the $\mathrm{TiO}_{2}$ film by successive ionic layer adsorption and reaction (SILAR) method [14]; SILAR method is a chemical method. The indium was doped in both the $\mathrm{PbS}$ and $\mathrm{CdS}$, characterization of the sample display that incorporating of Indium atoms would enhance absorption in the near-infrared portion. Using Pt counter electrode and polysulfide electrolyte to fabricate QDSC, the $J_{\mathrm{sc}}$ ballooned to $27.01 \mathrm{~mA} / \mathrm{cm}^{2}$ from $13.61 \mathrm{~mA} / \mathrm{cm}^{2}$ and the $V_{\text {oc }}$ was improved to $0.43 \mathrm{~V}$ from $0.37 \mathrm{~V}$ at the same time. Relative to other heterojunction cells $[15,16]$, we used the easier way to prepare doped heterojunction. 


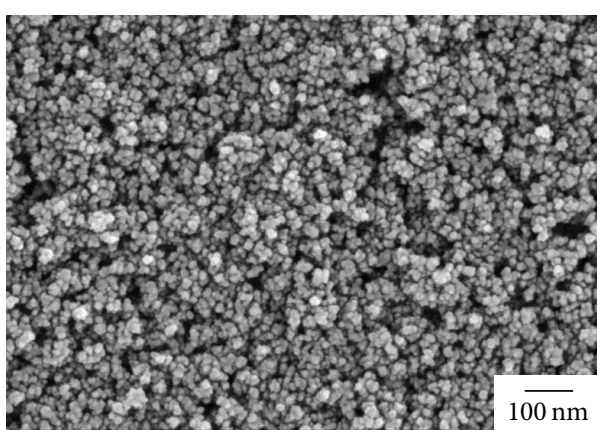

(a)

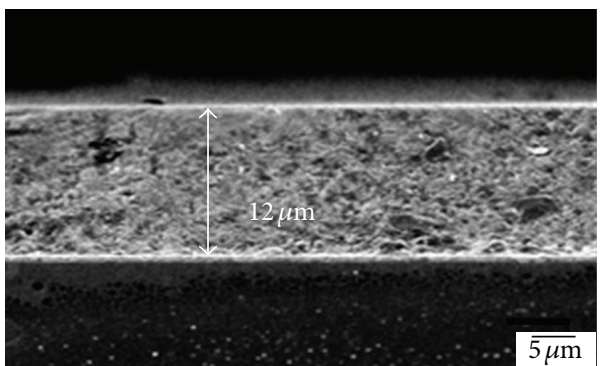

(c)

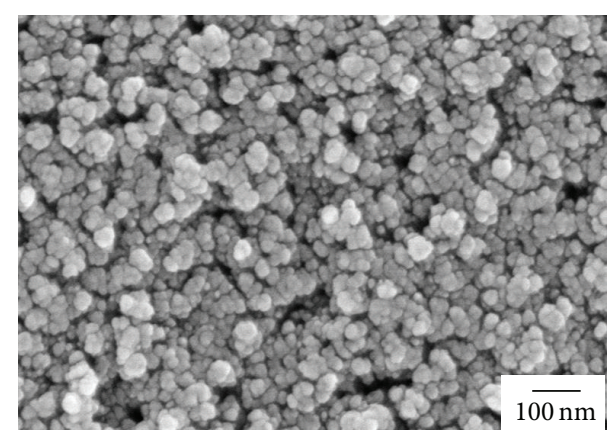

(b)

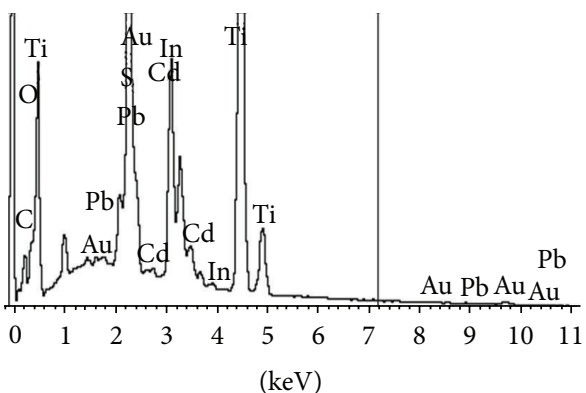

(d)

FIgURE 1: SEM image of (a) a bare $\mathrm{TiO}_{2}$ mesoporous film and (b) In-PbS/In-CdS sensitized $\mathrm{TiO}_{2}$ mesoporous film; (c) a cross-section SEM image of a bare $\mathrm{TiO}_{2}$ film; (d) the EDX spectra of In-PbS/In-CdS QD sensitized $\mathrm{TiO}_{2}$ film.

\section{Experimental Procedure}

The photoanode structure was $\mathrm{FTO} / \mathrm{TiO}_{2} / \mathrm{QDs}$; mesoporous $\mathrm{TiO}_{2}$ films were prepared by screen-printing of $\mathrm{TiO}_{2}$ paste (the size of $\mathrm{TiO}_{2}$ particle is about $20 \mathrm{~nm}$ ) on clear fluorinedoped tin oxide (FTO) substrates, followed by sintering at $450^{\circ} \mathrm{C}$ for $30 \mathrm{~min}$.

Quantum dots were deposited by successive ionic layer adsorption and reaction (SILAR) method. In brief, $0.1 \mathrm{M}$ lead nitrate or cadmium nitrate in methanol was used as cation source and $0.1 \mathrm{M}$ sodium sulfide in methanol as anion source. To incorporate doping of $\mathrm{In}^{3+}$, indium chloride $(0.01 \mathrm{M})$ was mixed with lead nitrate or cadmium nitrate. This allowed coadsorption of $\mathrm{In}^{3+}$ and $\mathrm{Pb}^{2+}$ (or $\mathrm{Cd}^{2+}$ ) ions, which in turn facilitated incorporation of $\mathrm{In}^{3+}$ in the $\mathrm{PbS}$ (or CdS). The dipping time in the $\mathrm{Pb}^{2+}$ and $\mathrm{S}^{2-}$ solution was $60 \mathrm{~s}$ for each, and the SILAR cycle was repeated 2 times; the dipping time in the $\mathrm{Cd}^{2+}$ and $\mathrm{S}^{2-}$ solution was $5 \mathrm{~min}$ for each, and the SILAR cycle was repeated 6 times.

The counter electrode was Pt coated FTO, which was prepared by doctor blading chloroplatinic acid on FTO glass, then sintering at $450^{\circ} \mathrm{C}$ for $30 \mathrm{~min}$. A solution of $0.5 \mathrm{M}$ sodium sulfide, $2 \mathrm{M}$ sulfur, and $0.2 \mathrm{M}$ potassium chloride dissolved in 1:1 methanol and water was used as the liquid electrolyte. The cells were assembled in sandwich fashion using a parafilm spacer. Solar cell performance was evaluated under simulated AM1.5 irradiation conditions.

\section{Results and Discussion}

We prepared four different heterojunction types on $\mathrm{TiO}_{2}$ film: (a) 2 SILAR cycles of PbS followed by 6 cycles of CdS $\left(\mathrm{TiO}_{2} / \mathrm{PbS} / \mathrm{CdS}\right),(\mathrm{b}) 2$ SILAR cycles of In-PbS followed by 6 cycles of $\mathrm{CdS}\left(\mathrm{TiO}_{2} / \mathrm{In}-\mathrm{PbS} / \mathrm{CdS}\right)$, (c) 2 SILAR cycles of $\mathrm{PbS}$ followed by 6 cycles of In-CdS ( $\left.\mathrm{TiO}_{2} / \mathrm{PbS} / \mathrm{In}-\mathrm{CdS}\right)$, and (d) 2 SILAR cycles of In-PbS followed by 6 cycles of In-CdS $\left(\mathrm{TiO}_{2} / \mathrm{In}-\mathrm{PbS} / \mathrm{In}-\mathrm{CdS}\right)$. Figure 1 (a) shows scanning electron micrograph (SEM) of a bare $\mathrm{TiO}_{2}$ mesoporous film. It is clear that the particle size of $\mathrm{TiO}_{2}$ ranges from $20 \mathrm{~nm}$ to $40 \mathrm{~nm}$. When In-PbS and In-CdS were assembled in the $\mathrm{TiO}_{2}$ film, a cluster of quantum dots in the surface was observed from the SEM images. This result indicates that a tiny amount of In-PbS and In-CdS was assembled in the SILAR process. A cross section SEM image of a bare $\mathrm{TiO}_{2}$ mesoporous film is shown in Figure 1(c), in which the $\mathrm{TiO}_{2}$ film thickness was clearly evident. Figure 1(d) presents energy dispersive $\mathrm{X}$-ray spectroscopy (EDX) results obtained from $\mathrm{TiO}_{2} / \mathrm{In}-\mathrm{PbS} / \mathrm{In}-\mathrm{CdS}$; EDX demonstrates the existence of In element in $\mathrm{PdS}$ or $\mathrm{CdS}$. The actual $\mathrm{Pb}, \mathrm{Cd}$, and In concentration as measured from the inductively coupled plasma optical emission spectroscopy, ICP-OES, analysis was found to be $7.383 \%, 45.5 \%$, and $0.97 \%$ in In-PbS/CdS QDs; $8.8143 \%, 47.86 \%$, and $5.48 \%$ in $\mathrm{PbS} / \mathrm{In}-\mathrm{CdS}$ QDs; and 6.49\%, $49.62 \%$, and $5.49 \%$ in In-PbS/In-CdS QDs. This indicates the incorporation of Indium into $\mathrm{PbS}$ and $\mathrm{CdS}$ quantum dots by 

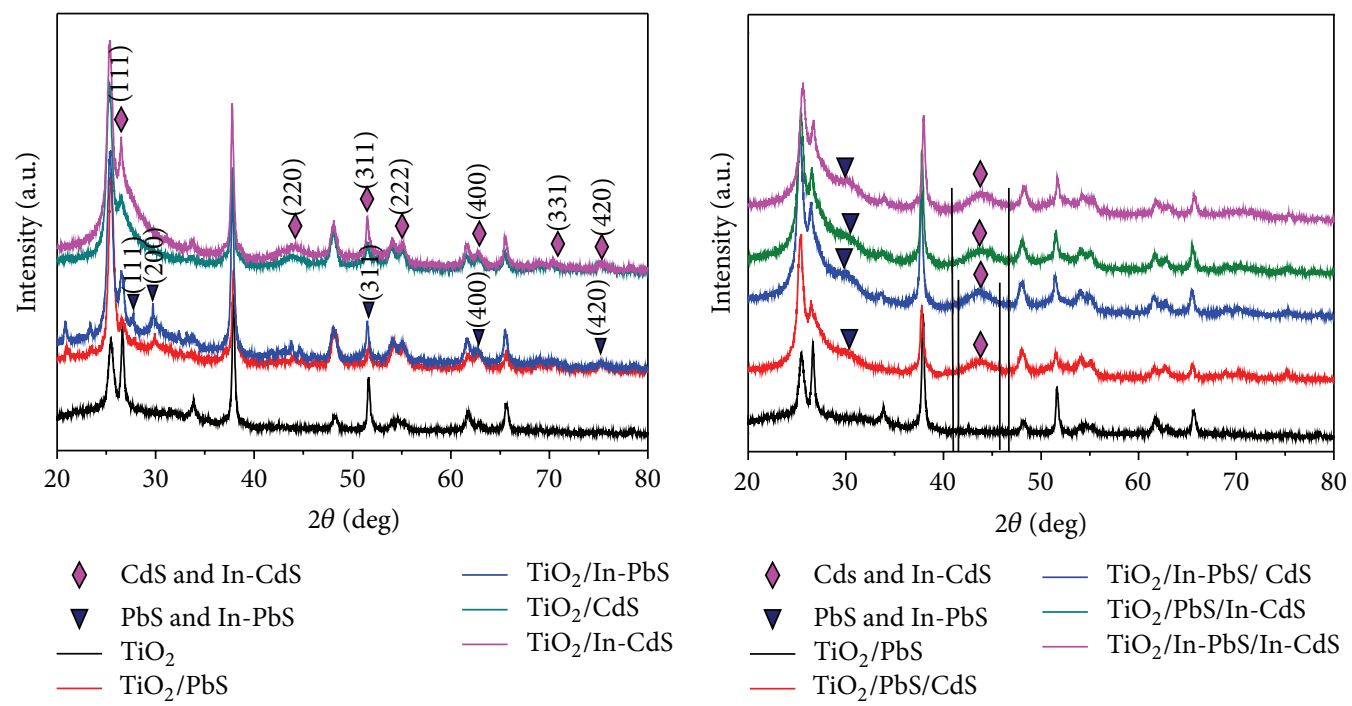

(a)

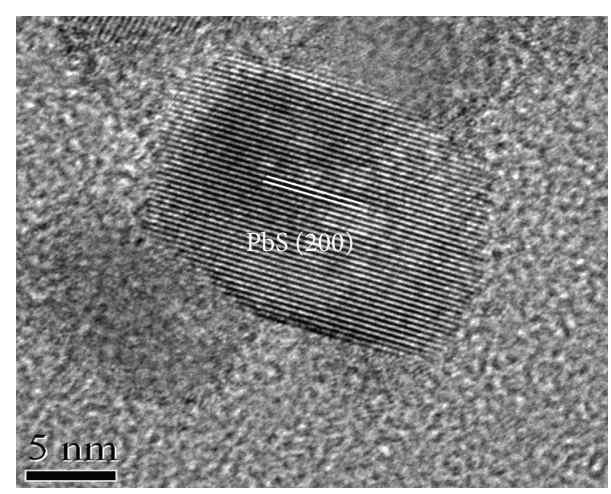

(c)

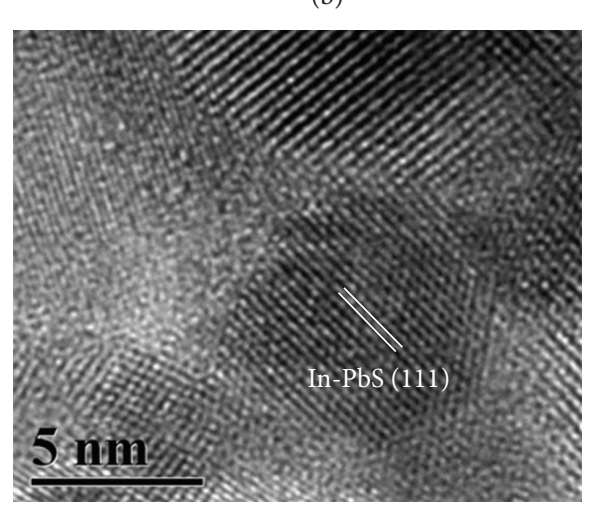

(d)

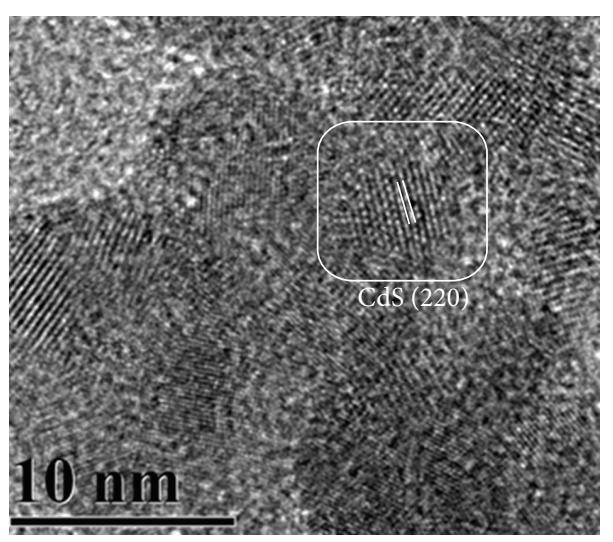

(e)

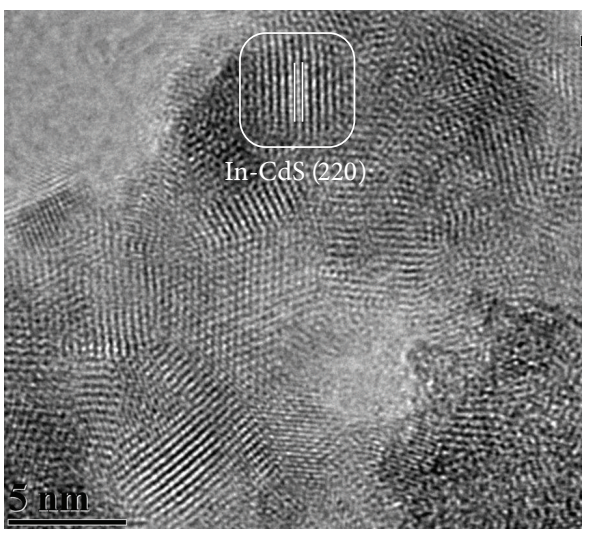

(f)

FIgure 2: The XRD patterns of (a) four QDs and $\mathrm{TiO}_{2}$ and (b) four heterojunctions and $\mathrm{TiO}_{2}$; the HRTEM of (c) PbS, (d) In-PbS; (e) CdS, and (f) In-CdS.

SILAR method. In addition, the concentration of $\mathrm{PbS}$ and CdS which was doped In atoms has no significant increase or decrease, while the concentration in solid film of In atoms would vary with SILAR cycles.

The X-ray diffraction (XRD) patterns are shown in Figure 2. The $\mathrm{XRD}$ patterns show the $\mathrm{PbS}$ and $\mathrm{CdS}$ all are cubic structure. The diffraction maximum peak of $\mathrm{PbS}$ is (200) at $27.834^{\circ}$, while the higher peaks of In-PbS are (111) and (200) at $26.76^{\circ}$ and $27.834^{\circ}$, respectively. However, the major peaks of CdS and In-CdS both are (220) at $43.972^{\circ}$, but a broadening of the peak of In-CdS relative to CdS is seen. Figure 2(b) is the XRD patterns of four heterojunctions. 


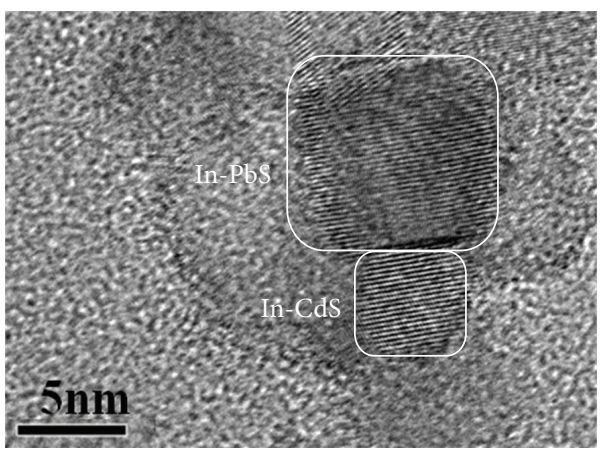

(a)

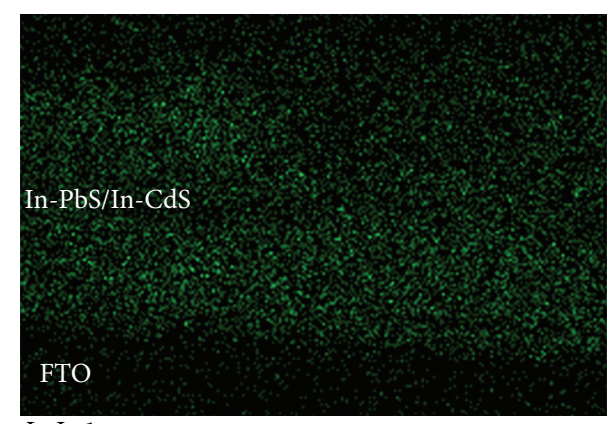

(b)

Figure 3: (a) The HRTEM of In-PbS/In-CdS and (b) the EDX mapping of the cross section In-PbS/In-CdS QD sensitized TiO ${ }_{2}$ film.

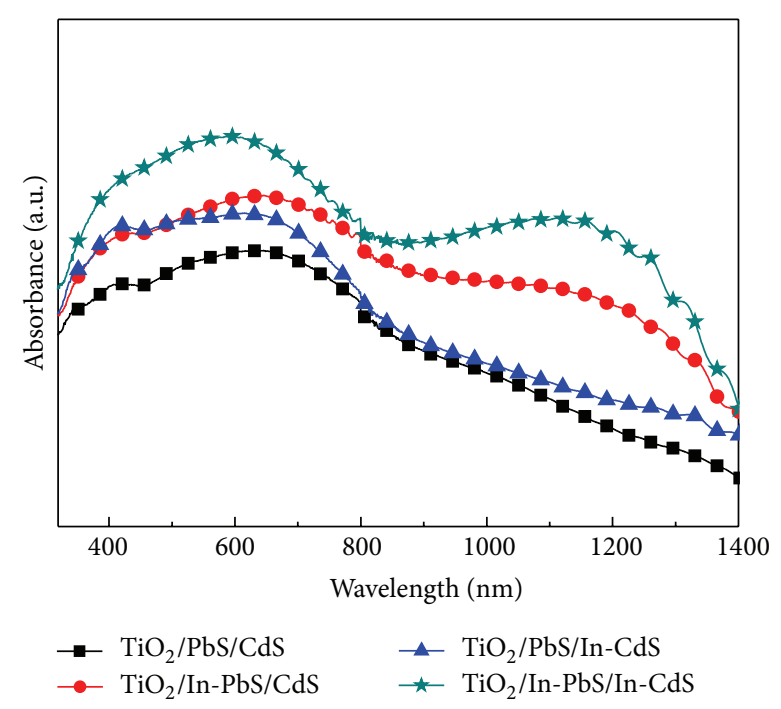

(a)

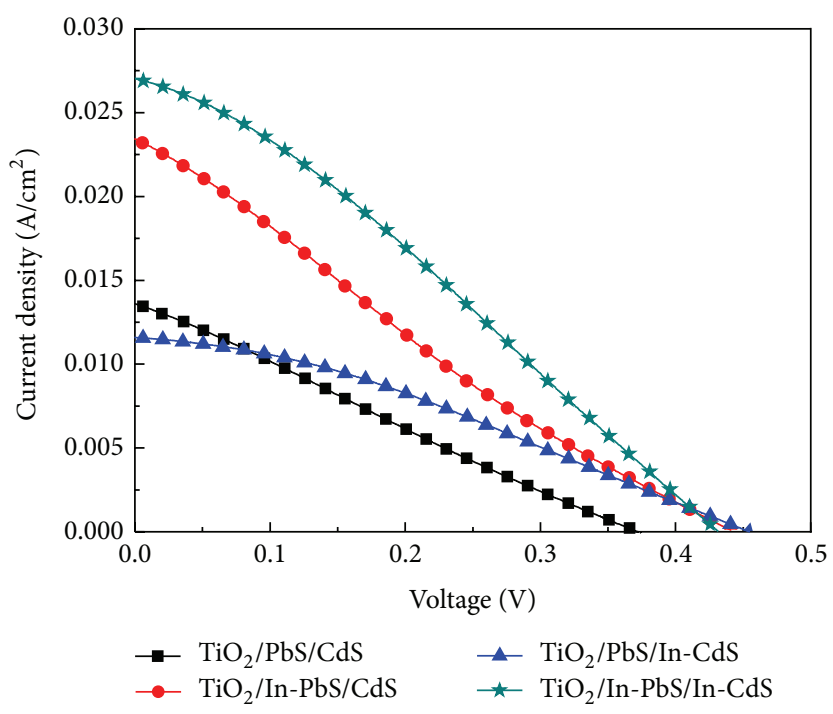

(b)

FIGURE 4: (a) Diffuse reflectance absorbance spectra of different QD sensitized films; (b) $J$ - $V$ characteristics of different working heterojunctions.

If In atoms were incorporated into $\mathrm{PbS}(\mathrm{In}-\mathrm{PbS} / \mathrm{CdS})$, the peak is moved to $26.76^{\circ}$ from $27.834^{\circ}$; this is because of the appearance of (111) peak of In-PbS at $26.76^{\circ}$, while the peak is broadened at $43.972^{\circ}$ after incorporating In atom into $\mathrm{CdS}(\mathrm{PbS} / \mathrm{In}-\mathrm{CdS})$; this is because of the broadening of the (220) peak of In-CdS. When both incorporate In atom into $\mathrm{PbS}$ and $\mathrm{CdS}$ (In-PbS/In-CdS), the peak is moved from $27.834^{\circ}$ to $26.76^{\circ}$ and is broadened at $43.972^{\circ}$. Because of lattice distortions or changes as a result of In doping, it can be confirmed that $\mathrm{PbS}$ or $\mathrm{CdS}$ has been incorporated. The high-resolution electron transmission electron microscopy (HRTEM) images of QDs also are shown in Figure 2. We can reckon that the particle size of $\mathrm{PbS}$ and $\mathrm{In}-\mathrm{PbS}$ is about $10 \mathrm{~nm}$ and $5 \mathrm{~nm}$, respectively, while the major peaks is different, that matches the change of XRD patterns. The particle size of $\mathrm{PbS}$ or In-PbS is surprisingly smaller than their Bohr radius [17]. The particle sizes of CdS and In-CdS are all about $5 \mathrm{~nm}$, which is bigger than their Bohr radius and smaller than $10 \mathrm{~nm}$ [18].
The HRTEM image of In-PbS/In-CdS QDs is shown in Figure 3(a). The information obtained from Figure 3(a) agrees with Figures 2(d) and 2(f). The EDX mapping of the cross section In-PbS/In-CdS QD sensitized $\mathrm{TiO}_{2}$ film is shown in Figure 3(b). The In element not only exists in film, but also is evenly distributed along depth. Such a distribution is not only because In-PbS or In-CdS were assembled in the $\mathrm{TiO}_{2}$ mesoporous by using SILAR but because same proportion indium chloride was mixed with lead nitrate or cadmium nitrate as a cation source.

The light absorption property of $\mathrm{PbS} / \mathrm{CdS}$ without or with In dopant sensitized $\mathrm{TiO}_{2}$ film is assessed by UVvis absorption spectra, Figure 4(a). The absorption property in the visible range increased when the $\mathrm{CdS}$ was doped (PbS/In-CdS); however, no apparent contrast increase was found in the long wavelength region. The absorption property for wavelength longer than $1000 \mathrm{~nm}$ increases greatly when the $\mathrm{PbS}$ was doped (In-PbS/CdS). But the absorption of 


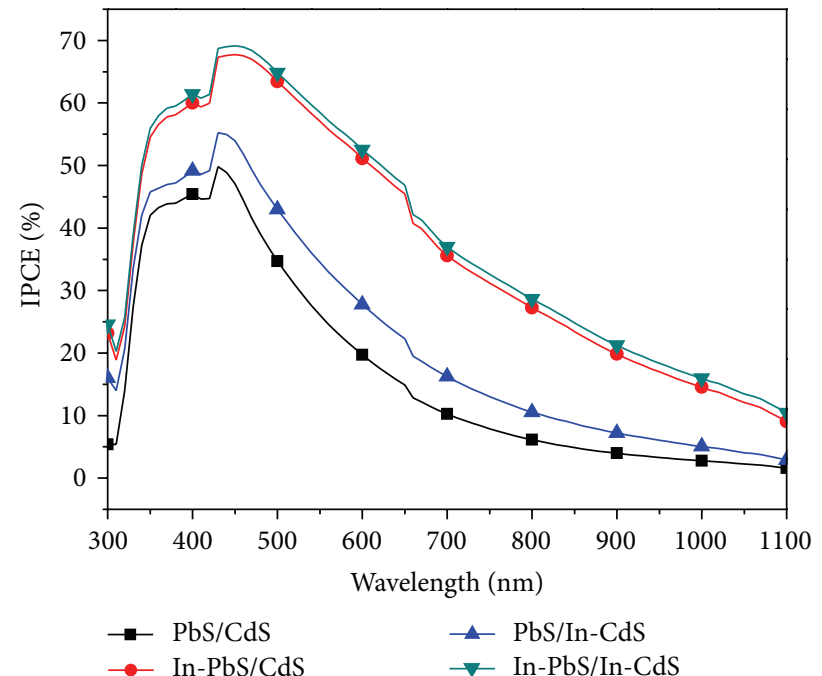

(a)

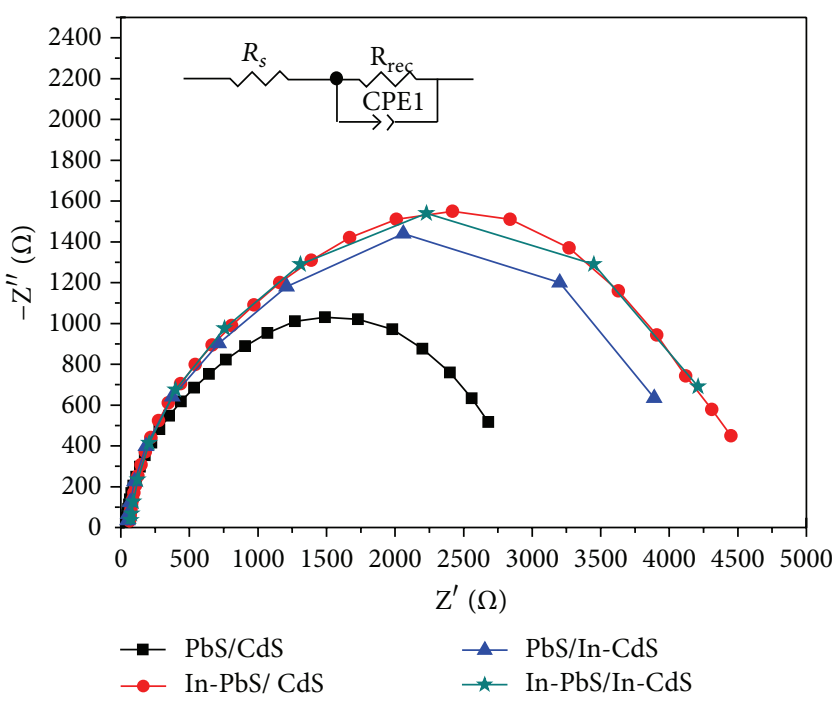

(b)

FIGURE 5: (a) IPCE spectra for four devices; (b) EIS spectra of QDSSCs measured in the dark at $-0.4 \mathrm{~V}$ bias voltages. The inset illustrates the equivalent circuit simulated. Rrec and CPE1 represent the charge transfer resistance and capacitance at $\mathrm{TiO}_{2} /$ electrolyte interface, respectively; $R_{s}$ is a series resistance.

TABLE 1: Different photovoltaic parameter for different working heterojunctions.

\begin{tabular}{lcccc}
\hline Samples & $J_{\text {sc }}\left(\mathrm{mA} / \mathrm{cm}^{2}\right)$ & $V_{\text {oc }}(\mathrm{V})$ & $\mathrm{FF}$ & $\eta(\%)$ \\
\hline $\mathrm{TiO}_{2} / \mathrm{PbS} / \mathrm{CdS}$ & 13.61 & 0.37 & 0.25 & 1.26 \\
$\mathrm{TiO}_{2} / \mathrm{In}-\mathrm{PbS} / \mathrm{CdS}$ & 23.4 & 0.44 & 0.23 & 2.36 \\
$\mathrm{TiO}_{2} / \mathrm{PbS} / \mathrm{In}-\mathrm{CdS}$ & 11.6 & 0.45 & 0.32 & 1.69 \\
$\mathrm{TiO}_{2} / \mathrm{In}-\mathrm{PbS} / \mathrm{In}-\mathrm{CdS}$ & 27.01 & 0.43 & 0.29 & 3.42 \\
\hline
\end{tabular}

In-PbS/CdS deposited film also increased in the visible range, which is due to the diffusion of indium atoms from In$\mathrm{PbS} / \mathrm{CdS}$ interface where In is not stable into CdS quantum dot [19]. Both the PbS and CdS were incorporated with indium (In-PbS/In-CdS), not only increased the light absorption in the visible range, and an absorption peak has emerged in the near-infrared portion. ICP-OES analysis illustrates that the concentration of $\mathrm{PbS}$ and $\mathrm{CdS}$ has no significant increase or decrease; it is excluded that the higher light adsorption was attributed to the possibility of the increase of PdS or CdS for the "doped" samples compared with the undoped ones fabricated via SILAR process, while, the absorption peak emerged in the near-infrared portion is the absorption peak of the exciton of the In-PbS QD.

The $J-V$ characteristics of these four QDSCs are presented in Figure 4(b). The $J_{\mathrm{sc}}, V_{\mathrm{oc}}$, fill factor (FF), and power conversion efficiency $(\eta)$ are summarized in Table 1 . An increase of $V_{\mathrm{oc}}$ is seen in the cells that incorporate foreign atoms. Similarly, cells that the $\mathrm{PbS}$ with indium atoms exhibited a significant increase in the photocurrent as compared to the corresponding cells without indium atoms. The absorption property has been able to explain why the higher $J_{\mathrm{sc}}$ was achieved in this study. However, PbS/In-CdS films exhibited decrease in the photocurrent and great increase in the $J_{\mathrm{sc}}$, which is due to an accumulation of photo-generated electron in QD layers, but improve the $V_{\text {oc }}$. As we expect, doped heterojunction used in solar cells can significantly increase $J_{\text {sc }}$ and the $V_{\text {oc }}$ was improved at the same time; an energy conversion efficiency of $3.42 \%$ was achieved.

The incident photon to carrier conversion efficiency (IPCE) recorded at different incident light wavelengths for QDSC that employ four different photo-anodes is shown in Figure 5(a). The overall photocurrent response matches the absorption features; IPCE values as high as $70 \%$ can be achieved by the $\mathrm{TiO}_{2} / \mathrm{In}-\mathrm{PbS} / \mathrm{In}$-CdS device. Significant retaining in IPCE is seen for $\mathrm{TiO}_{2} / \mathrm{In}-\mathrm{PbS} / \mathrm{In}$-CdS device with $10 \%$ at $1100 \mathrm{~nm}$. It is worth noting that the IPCE of $\mathrm{TiO}_{2} / \mathrm{PbS} / \mathrm{In}-\mathrm{CdS}$ is higher than undoped ones, but the $J_{\text {sc }}$ is lower. As we know, the IPCE represents how many electrons were generated when a photon was absorbed. So the $\mathrm{TiO}_{2} / \mathrm{PbS} / \mathrm{In}$-CdS generated more electrons, but they could not transport completely to FTO. There are two reasons; the impurity energy level is lower than conduction band of $\mathrm{TiO}_{2} / \mathrm{PbS} / \mathrm{CdS}$; some of the electrons accumulated on the impurity energy level to improve $V_{\mathrm{oc}}$. On the other hand, the electron on the conduction band of In-CdS would be back to impurity energy level to combine with the hole. As we expect, doped heterojunction used in solar cells can significantly broaden scope of light harvest into near-infrared portion and promote IPCE at long wavelength. Figure 5(b) shows the electrochemical impedance spectroscopy (EIS) of QDSSCs based on PbS/CdS, In-PbS/CdS, PbS/In-CdS, and In-PbS/In-CdS electrodes measured in the dark at $-0.4 \mathrm{~V}$ bias voltages. The equivalent circuit simulated which applies to the impedance spectroscopy was inset of Figure 5(b); Rrec and CPE1 represent the charge transfer resistance and capacitance at $\mathrm{TiO}_{2}$ /electrolyte interface, respectively; $R_{s}$ is series resistance that would account for the transport 


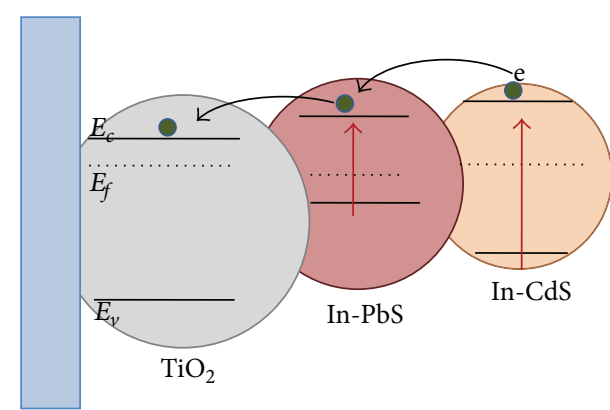

(a)

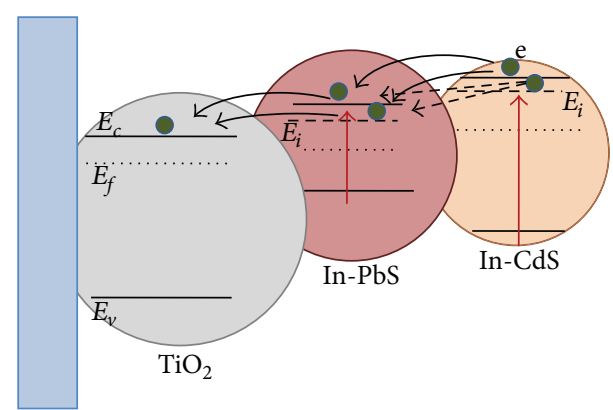

(b)

Figure 6: The schematic illustration of the carrier transfer in the (a) $\mathrm{TiO}_{2} / \mathrm{PbS} / \mathrm{CdS}$ film and (b) $\mathrm{TiO}_{2} / \mathrm{In}-\mathrm{PbS} / \mathrm{In}-\mathrm{CdS}$ film. Black arrow showed the electron transport; red arrow showed the electron transition.

resistance of FTO and the connection setup. It can be noticed that incorporating of indium atoms would enhance the value of the Rrec, which indicates that the recombination rate of electrons is slower than undoped ones. But seldom is a major change in the value of the $R_{s}$.

Figure 6(a) shows the schematic illustration of the electron transfer model for $\mathrm{TiO}_{2} / \mathrm{PbS} / \mathrm{CdS}$ film. PbS QDs and CdS QDs absorb photon to create pairs of electrons and holes, the electron transports to $\mathrm{TiO}_{2}$ from QDs, and then the electron transports to FTO from $\mathrm{TiO}_{2}$. The hole transports to electrolyte from QDs. The $\mathrm{TiO}_{2}$ particles are designed to give a large surface area for QDs to grow on. In addition, $\mathrm{TiO}_{2}$ particles are the transporting layer of the electron. As shown in Figure 5(b), the impurity energy level is the presence in $\mathrm{PbS}$ or CdS QD. The presence of impurity energy level not only increased the light absorption in the near-infrared portion, but also improves transmission dynamics of electron and transport path between two nanoparticles. Most electrons were transport to FTO; the combination rate of electrons in film would be slower. So the $J_{\mathrm{sc}}$ ballooned to $27.01 \mathrm{~mA} / \mathrm{cm}^{2}$ of $\mathrm{TiO}_{2} / \mathrm{In}-\mathrm{PbS} / \mathrm{In}-\mathrm{CdS}$ devices. The presence of impurity energy level will accumulate electron within the QD layers, thus shifting the Fermi level to more negative potentials and increasing the conduction band of CdS. The $V_{\text {oc }}$ of $\mathrm{TiO}_{2} / \mathrm{In}$ $\mathrm{PbS} / \mathrm{In}$-CdS device was improved.

There is no doubt that incorporated heterojunction used in QDSCs would significantly increase the $J_{\mathrm{sc}}$; the $V_{\mathrm{oc}}$ have an improvement at the same time. Although such a high $J_{\text {sc }}$ is rare, it can be further increased to prevent exciton fast recombining to, such as coat with $\mathrm{ZnS}$ or dyes at the outer surface of CdS [20]. In addition, the power conversion efficiency can be also enhanced by improve electrolyte and counter electrode $[8,9]$.

\section{Conclusion}

A foreign atom-indium atom was incorporated into $\mathrm{PbS} /$ CdS QDs to prepare In-PbS/In-CdS heterojunction by successive ionic layer adsorption and reaction method which is a chemical method. Experimental results indicate that $\mathrm{PbS}$ or $\mathrm{CdS}$ has been doped with In by SILAR method; the concentration of $\mathrm{PbS}$ and $\mathrm{CdS}$ which was doped $\mathrm{In}$ atoms has no significant increase or decrease. In addition, incorporating of indium atoms has resulted in the lattice distortions or changes of $\mathrm{PbS}$ or $\mathrm{CdS}$ and improved the light harvest of heterojunction. Using this heterojunction, $\mathrm{Pt}$ counter electrode and polysulfide electrolyte to fabricate quantum dot sensitized solar cells, the short circuit current density ballooned to $27.01 \mathrm{~mA} / \mathrm{cm}^{2}$ from $13.61 \mathrm{~mA} / \mathrm{cm}^{2}$, and the open circuit voltage was improved to $0.43 \mathrm{~V}$ from $0.37 \mathrm{~V}$ at the same time.

\section{Conflict of Interests}

The authors declare that there is no conflict of interests regarding the publication of this paper.

\section{Acknowledgments}

This work was partially supported by Key Project of Beijing Natural Science Foundation (3131001), Key Project of Natural Science Foundation of China (91233201 and 61376057), Key Project of Beijing Education Committee Science \& Technology Plan (KZ201211232040), State 863 Plan of MOST of PR China (2011AA050527), Beijing National Laboratory for Molecular Sciences (BNLMS2012-21), State Key Laboratory of Solid State Microstructures of Nanjing University (M27019), State Key Laboratory for Integrated Optoelectronics of Institute of Semiconductors of CAS (IOSKL2012KF11), State Key Laboratory for New Ceramic and Fine Processing of Tsinghua University (KF1210), Key Laboratory for Renewable Energy and Gas Hydrate of Chinese Academy of Sciences (y207ka1001), Beijing Key Laboratory for Sensors of BISTU (KF20131077208), and Beijing Key Laboratory for Photoelectrical Measurement of BISTU (GDKF2013005).

\section{References}

[1] N. S. Karan, D. D. Sarma, R. M. Kadam, and N. Pradhan, "Doping transition metal ( $\mathrm{Mn}$ or $\mathrm{Cu})$ ions in semiconductor nanocrystals," Journal of Physical Chemistry Letters, vol. 1, no. 19, pp. 2863-2866, 2010.

[2] V. Chikan, "Challenges and prospects of electronic doping of colloidal quantum dots: Case study of CdSe," Journal of Physical Chemistry Letters, vol. 2, no. 21, pp. 2783-2789, 2011. 
[3] S. Roy, C. Tuinenga, F. Fungura, P. Dagtepe, V. Chikan, and J. Jasinski, "Progress toward producing n-type CdSe quantum dots: Tin and indium doped CdSe quantum dots," Journal of Physical Chemistry C, vol. 113, no. 30, pp. 13008-13015, 2009.

[4] Y. Justo, B. Goris, J. S. Kamal, P. Geiregat, S. Bals, and Z. Hens, "Multiple dot-in-rod PbS/CdS heterostructures with high photoluminescence quantum yield in the near-infrared," Journal of the American Chemical Society, vol. 134, no. 12, pp. 5484-5487, 2012.

[5] W. Lee, W.-C. Kwak, S. K. Min et al., "Spectral broadening in quantum dots-sensitized photoelectrochemical solar cells based on CdSe and Mg-doped CdSe nanocrystals," Electrochemistry Communications, vol. 10, no. 11, pp. 1699-1702, 2008.

[6] R. Zeng, M. Rutherford, R. Xie, B. Zou, and X. Peng, "Synthesis of highly emissive Mn-Doped ZnSe nanocrystals without pyrophoric reagents," Chemistry of Materials, vol. 22, no. 6, pp. 2107-2113, 2010.

[7] Z. Huang, X. Zou, and H. Zhou, "A strategy to achieve superior photocurrent by $\mathrm{Cu}$-doped quantum dot sensitized solar cells," Materials Letters, vol. 95, pp. 139-141, 2013.

[8] A. Braga, S. Giménez, I. Concina, A. Vomiero, and I. MoraSeró, "Panchromatic sensitized solar cells based on metal sulfide quantum dots grown directly on nanostructured $\mathrm{TiO} 2$ electrodes," Journal of Physical Chemistry Letters, vol. 2, no. 5, pp. 454-460, 2011.

[9] J. W. Lee, D. Y. Son, and T. K. Ahn, "Quantum-dot-sensitized solar cell with unprecedentedly high photocurrent," Scientific Reports, vol. 3, article 1050, 2013.

[10] P. K. Santra and P. V. Kamat, "Mn-doped quantum dot sensitized solar cells: a strategy to boost efficiency over 5\%," Journal of the American Chemical Society, vol. 134, no. 5, pp. 2508-2511, 2012.

[11] H. J. Lee, P. Chen, S.-J. Moon et al., "Regenerative PbS and CdS quantum dot sensitized solar cells with a cobalt complex as hole mediator," Langmuir, vol. 25, no. 13, pp. 7602-7608, 2009.

[12] J. Gao, J. M. Luther, O. E. Semonin, R. J. Ellingson, A. J. Nozik, and M. C. Beard, "Quantum dot size dependent J-V characteristics in heterojunction $\mathrm{ZnO} / \mathrm{PbS}$ quantum dot solar cells," Nano Letters, vol. 11, no. 3, pp. 1002-1008, 2011.

[13] S. Baidyaroy and P. Mark, "Analytical and experimental investigation of the effects of oxygen chemisorption on the electrical conductivity of CdS," Surface Science, vol. 30, no. 1, pp. 53-68, 1972.

[14] H. M. Pathan and C. D. Lokhande, "Deposition of metal chalcogenide thin films by successive ionic layer adsorption and reaction (SILAR) method," Bulletin of Materials Science, vol. 27, no. 2, pp. 85-111, 2004.

[15] A. H. Ip, S. M. Thon, S. Hoogland et al., "Hybrid passivated colloidal quantum dot solids," Nature Nanotechnology, vol. 7, pp. 577-582, 2012.

[16] L. Y. Chang, R. R. Lunt, P. R. Brown, V. Bulovic, and M. G. Bawendi, "Low-temperature solution-processed solar cells based on PbS colloidal quantum Dot/CdS heterojunctions," Nano Letters, vol. 13, no. 3, pp. 994-999.

[17] W. W. Frank, "Lead salt quantum dots: the limit of strong quantum confinement," Accounts of Chemical Research, vol. 33, no. 11, pp. 773-780, 2000.

[18] X. Xu, Y. Zhao, E. J. Sie et al., "Dynamics of bound exciton complexes in CdS nanobelts," ACS Nano, vol. 5, no. 5, pp. 3660$3669,2011$.

[19] J. N. David, L. E. Alexander, and C. E. Steven, Accounts of Chemical Research, vol. 33, pp. 773-780, 2000.
[20] N. Guijarro, J. M. Campiña, Q. Shen et al., "Uncovering the role of the $\mathrm{ZnS}$ treatment in the performance of quantum dot sensitized solar cells," Physical Chemistry Chemical Physics, vol. 13, no. 25, pp. 12024-12032, 2011. 

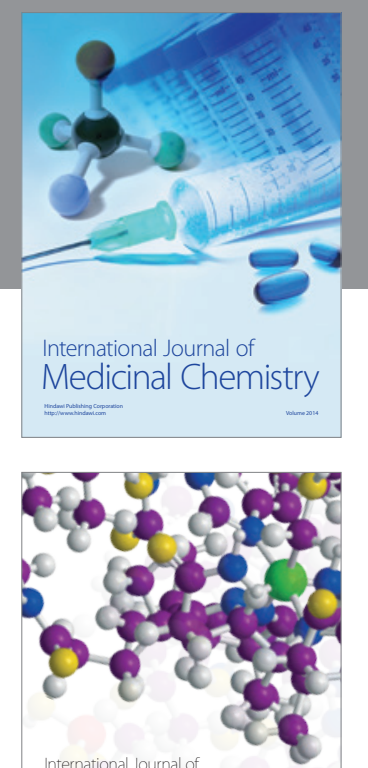

\section{Carbohydrate} Chemistry

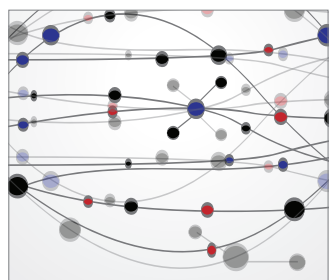

The Scientific World Journal
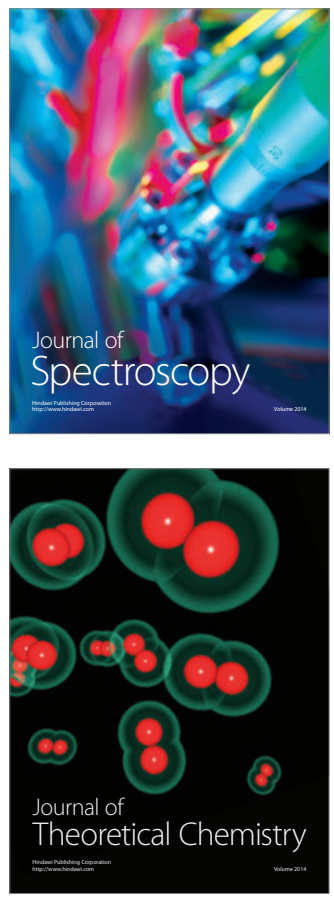
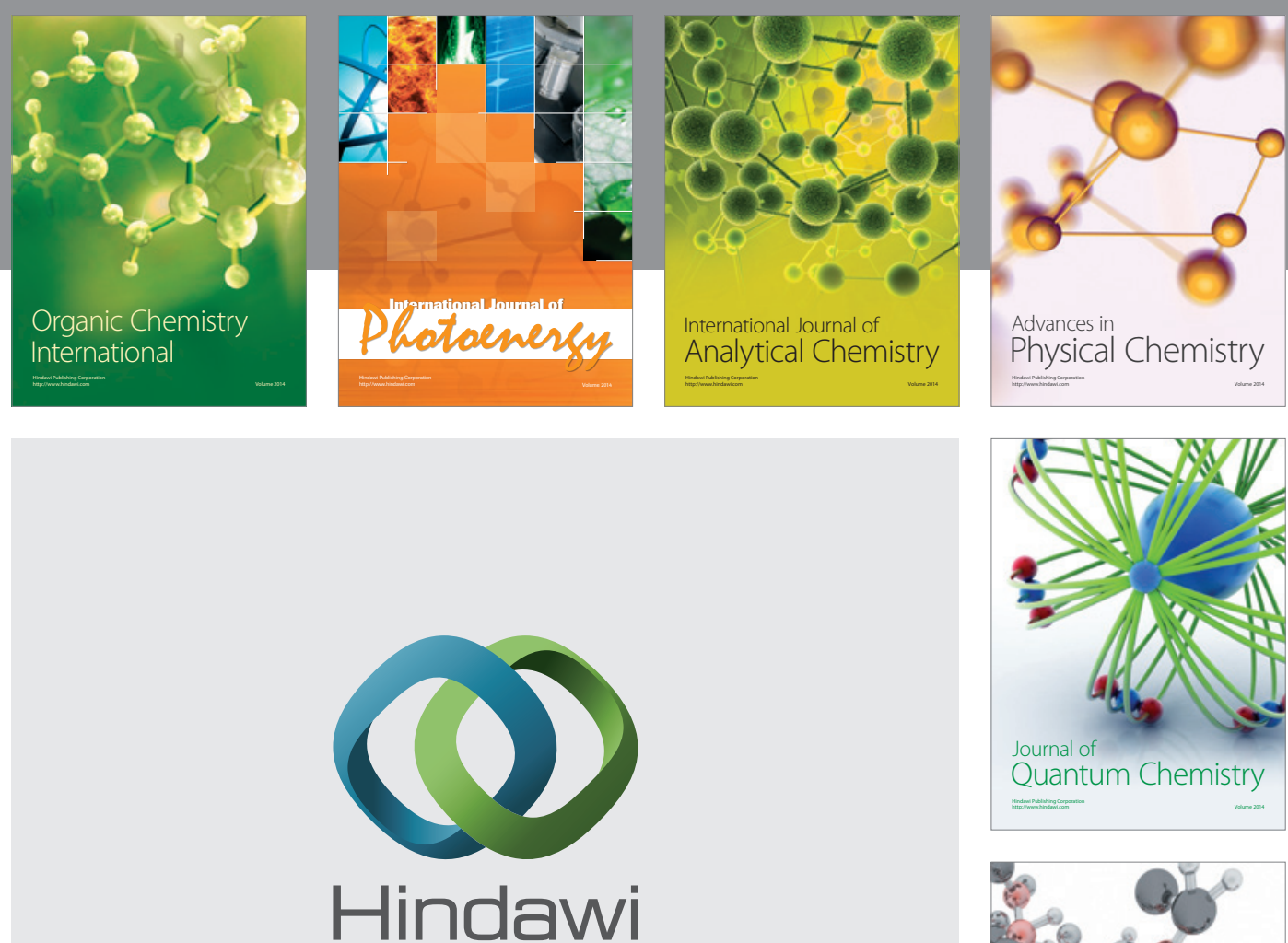

Submit your manuscripts at

http://www.hindawi.com

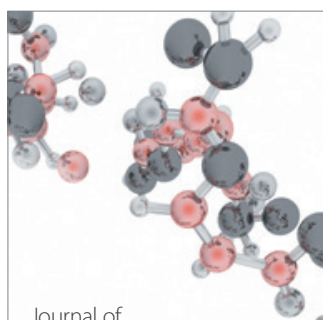

Analytical Methods

in Chemistry

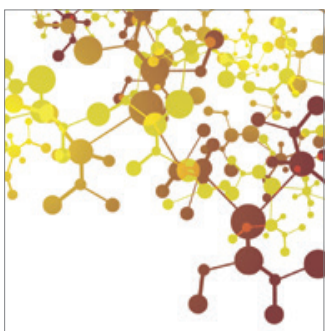

Journal of

Applied Chemistry

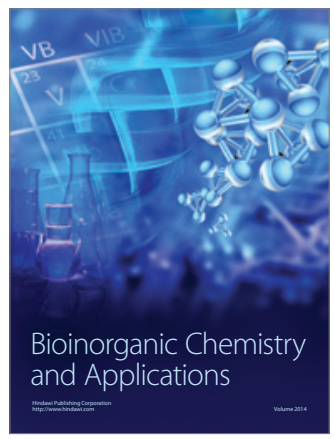

Inorganic Chemistry
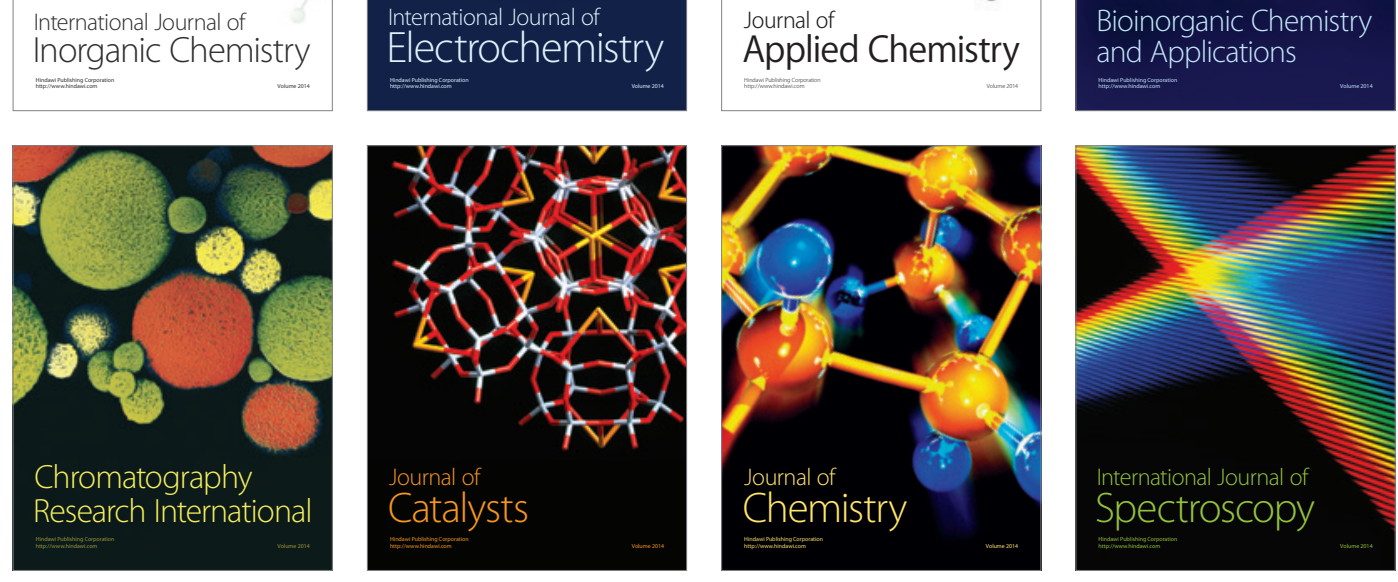